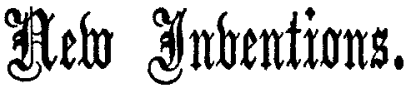

\section{WIRE SUTURE-CASE.}

To facilitate wire suturing I have devised a case containing in small compass all my instruments for suturing fractures, whether of maxillæ, patellæ, or long bones. It has been made to pattern by Messrs. S. Maw, Son and Thompson and has been so arranged that the inside tray may be lifted out and its contents boiled in the steriliser without disturbance. The case contains bayonet-shaped drills, silver sutures of varying

FIG. 1.

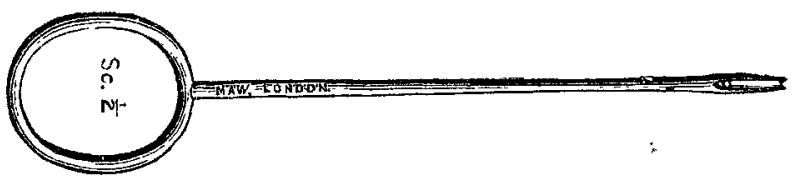

thickness, pliable needle, forceps, \&c. The needle (Fig. 1) is made of plated copper-wire, with an eyelet at one end. This having been passed through the second drill-hole may be threaded for the purpose of returning the wire. Being of soft metal the needle is readily bent to any required angle. The spoon (Fig. 2) protects the tissues by receiving the point of the drill and also of the wire and

FIG. 2.

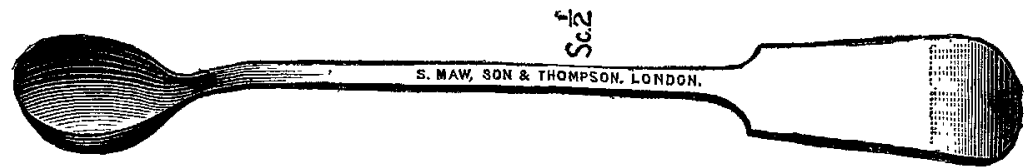

gives the latter a turn in the desired direction. The wire may then be seized and lifted from the floor of the mouth or depth of wound by the long-bladed forceps (Fig. 3).

FIG. 3.

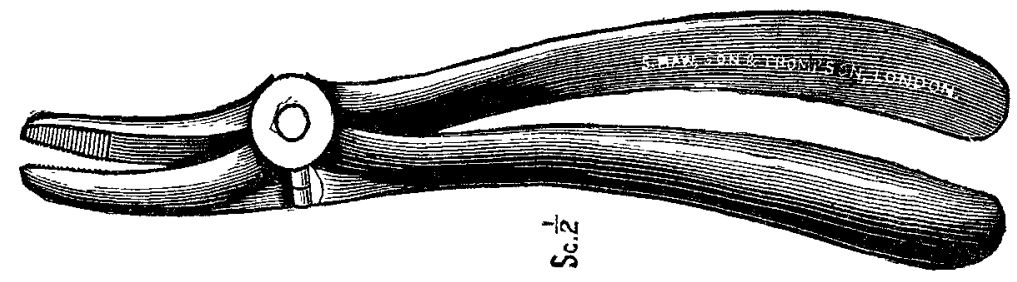

When the suture is ready for twisting the key (Fig. 4) may

FIG. 4.

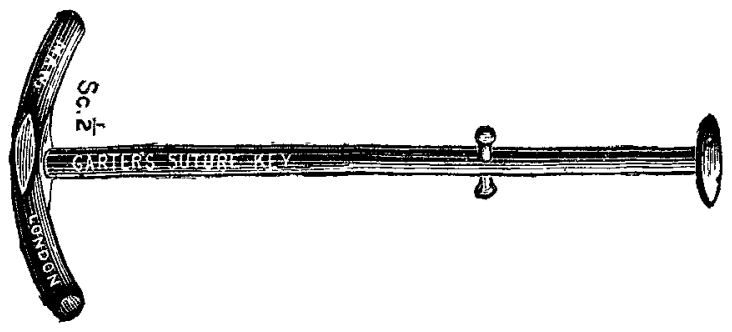

be used in the manner described in THE LANCET of Feb. 26th, 1898, p. 571 (also Dec. 3rd, 1892, p. 1266). The side cutters (Fig. 5) sever the suture at any required point.

FIG. 5.

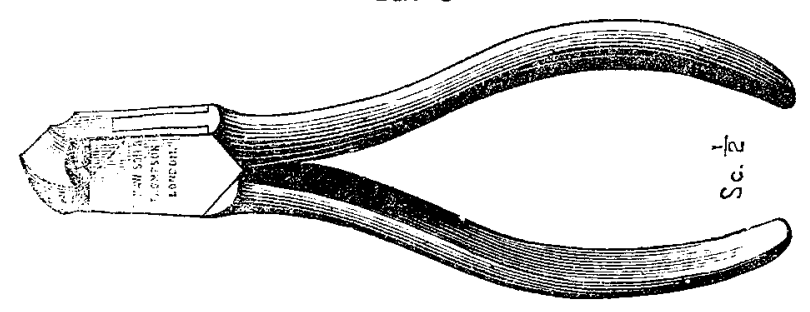

Hitherto there have been two great difficulties in the wiring of bones-(1) the drilling and (2) the return of the wire through the second channel made. The first I have overcome by using a dental engine and the second by devising the instruments described above.

T. S. CARTER, L.D.S.R:C.S. Eng.,

Honorary Dental Surgeon to the General Infirmary, Leeds.

\section{EXHIBITION O ROENTGEN RAY WORK AT EDINBURGH.}

AN interesting feature of the Pathological Museum at the meeting of the British Medical Association at Edinburgh was a collection of skiagrams which abundantly illustrated the wide range and usefulness of this new aid to diagnosis. Mr. Noble Smith sent a technically excellent series of congenital dislocations of the hip, together with a case of coxa vara, the exact nature of which could be established only by the photograph. Dr. Macintyre of Glasgow showed the transposition of viscera in a youth whose age was not stated. This beautiful photograph, about 16 in. by 24 in., was evidently taken with the patient in the prone position. One interesting point was that the ribs were clearly shown even in front of the liver.

Mr. Lynn Thomas sent eleven instances of Colles's fracture which showed that the styloid process of the ulna is often broken off in that injury. A child's arm with deformity like that of Colles's fracture was found to have a transverse fracture of the radius higher up than the site originally described by that surgeon. This latter point was also clearly brought out by Mr. Griffith Wilkin (London). Mr. Alexander Miles exhibited a characteristic skiagram of a case of double knockknee which demonstrated how such a photograph of the bones might guide the surgeon before operation. He also showed an example of bad union of a femur fractured below the trochanter which revealed the exact state of affairs with striking effect. Dr. Walsh sent two instructive skiagrams taken in a medico-legal case where an unsuccessful attempt was made to detect an alleged fracture of the ribs over the liver. An aneurysm of the aorta was discovered, however, and a record obtained of extensive bronchiectatic cavities in the lung. Dr. Dawson Turner sent some beauti. ful stereoscopic Roentgen photographs of the injected bloodvessels of the principal organs of the body. His method is to inject in the ordinary way and then to take Roentgen photographs from different points of view. Either the object or the focus-tube must be displaced laterally in taking the second photograph. He used a displacement of 6.6 inches with the tube 12 inches from the sensitive plate. A Wheatstone stereoscope yielded a remarkable effect in liver, heart, and kidneys. This method would probably yield good results in the case of embedded foreign bodies. Dr. Harry Rainy and Mr. H. J. Stiles sent an excellent series of mercurial injections of the blood-vessels of the human body. These photographs had a distinct educational value and furnished a bird's. eye view of the arterial circulation. The same gentlemen contributed a set of skiagrams illustrating various diseases of bone and showing how, owing to rarefaction or sclerosis, it was possible to define many morbid processes which must have remained doubtful apart from operative interference. A gumma of the ulna showed the irregular erosion of the bone in the centre of the growth and a fresh formation (sclerosing osteitis) at the edges and presented a clear picture of the pathological changes which were taking place. An old Colles's fracture displayed wonderful bone texture and compared favourably with the best work shown at the societies. An interesting case revealed destruction of epiphyses in a child's hand injured by frost-bite. By contrast with the unaffected hand the epiphyses were seen to have gone more or less completely from the base of the first and second thumb phalanges and the base of the first phalanx of the forefinger. An abscess of the calf showed a large diffuse shadow in the substance of a greatly enlarged calf. The soft tissue of the boot came out admirably, so that even the stitches were visible. One remarkable photograph was that of a stunted hand of which the bones were greatly thickened and bossed. The bones of a male dwarf, twenty-three years of age, displayed little advance in ossification over those of a rickety girl ten years of age. A case skiagraphed by Dr. Thompson showed the character of a fracture in the upper part of the tibia, thereby affording valuable indications for treatment. Dr. Steven (Glasgow) exhibited a good and clear photograph of hypertrophic (non-pulmonary) osteo-arthropathy ; there was subperiosteal new formation of bone in the radius and the metacarpal bones. Taken as a whole the collection afforded an excellent survey of the present position of Roentgen photography in the world of scientific medicine. 